\title{
Individual Heat and Combined Heat Drought Stresses in Wheat: Variation in NDVI and Canopy Temperature
}

\author{
S. Gurumurthy ${ }^{1 *}$, Ajay Arora ${ }^{1}$, Basudeb Sarkar ${ }^{2}$, Harikrishna ${ }^{1}$, V.P. Singh ${ }^{1}$, \\ S.K. Meena ${ }^{3}$, Prakash Kumar ${ }^{4}$ and P.K. Singh ${ }^{1}$ \\ ${ }^{1}$ Indian Agricultural Research Institute, New Delhi, India \\ ${ }^{2}$ Central Research Institute for Dryland Agriculture, Hyderabad, Telangana, India \\ ${ }^{3}$ Indian Institute of Pulses Research, Kanpur, India \\ ${ }^{4}$ Indian Agricultural Statistics Research Institute, New Delhi, India
}

*Corresponding author

A B S T R A C T

The present study was conducted to determine genotypic variations for normalized difference vegetation index (NDVI) and canopy temperature (CT) in wheat under terminal

\section{Keywords}

Heat stress, Combined stress, NDVI, Canopy temperature

Article Info

Accepted:

20 September 2018

Available Online:

10 October 2018 heat and combined heat and drought stresses. Forty-four wheat genotypes were evaluated under late sown with irrigation (heat stress) and without irrigation (combined heat and drought stress) in an environment with average temperatures of $28.6^{\circ} \mathrm{C}$ during the growing season and $30.62^{\circ} \mathrm{C}$ during the grain filling stage. Moisture under heat stress range from 14.84 to $19.12 \%$ whereas under combined stress it was 5.08 to $10.49 \%$. The mean grain yield was 106.7 and $123.4 \mathrm{gm} /$ plot under heat stress and combined stress respectively. The mean CT 24.1 and $29.4^{\circ} \mathrm{C}$ was under heat stress and combined stress respectively. The mean NDVI 0.57 and 0.50 under heat stress and combined stress respectively. Overall, under combined stress there was a $13 \%$ decrease in NDVI, $18 \%$ increase in the CT and $13.5 \%$ increase in the yield than the heat stressed genotypes. The negative correlation between NDVI and yield whereas positive correlation between CT and grain yield under combined stress. The NDVI and CT are the two physiological traits to measure high yielding genotypes under combined stress.

\section{Introduction}

Wheat production is mostly limited by water availability, high temperature and combined heat and drought stresses. As a result of climate change, the frequency and intensity of drought and high temperatures are projected to increase on a global scale in the next decades. Negative changes are expected to be larger in lowland tropical regions (Rosenzweig et al.,
2014 and Porter et al., 2014). A large portion of such losses can be avoided through crop improvement. The association between heat and drought stress is poorly understood. Drought stress is often a combination of low water availability and increased temperature resulting from reduced transpirational cooling under limited water conditions. However, there is evidence that the response to drought stress at elevated ambient temperatures is 
unique and cannot be extrapolated from the sum of the effects of both stresses (Rizhsky, Liang, and Mittler 2002, 2004; Barnabas, Jaeger, and Feher 2008; Cairns et al., 2013). Three traits that can potentially be used in a wheat improvement program for tolerance to combined stress of heat and drought are canopy temperature and the normalized differential vegetation index (NDVI) and grain yield. Using selection indices like as $\mathrm{CT}$ and NDVI in conjunction with GY, will improve selection gains and increase cost efficiency of breeding programs (Neiff et al., 2015).

Canopy temperature (CT) is a useful indicator of crop water status (Jackson et al., 1977) and has potential as a tool for indirect selection of genotypes tolerant to drought and heat stressed environments (Reynolds et al., 2009). Developing cultivars with improved adaptation to drought and heat stressed environments is a priority for plant breeders. Canopy temperature (CT) is a useful tool for phenotypic selection of tolerant genotypes, as it integrates many physiological responses into a single low-cost measurement. Canopy temperature strongly depends on stomatal conductance and the plant's access to water. This makes canopy temperature a potential trait for indirect selection of maize germplasm for improved drought resistance (Garrity and O'Toole 1995). Different vegetative indices have the potential to be used to address wheat improvement; (i) the Normalized Difference Vegetative Index (NDVI) is the ratio between distinctive reflectance characteristics of the crop canopy in the red and near-infrared (NIR) region of the spectrum (Henik et al., 2012).

Grain yield is the most important trait for selection in crop improvement programs. Heritability for grain yield under stress is typically lower than that under optimal conditions, reducing genetic gain from selection under abiotic stress conditions (Weber et al., 2012). The specific objectives of this study were to identify vegetative indices measured with high throughput devices that could potentially be used as alternative to visual scores taken by breeders.

\section{Materials and Methods}

\section{Wheat germplasm and experimental design}

The field experiment was carried at new area of ICAR-Indian Agricultural Research Institute, New Delhi, India $\left(28^{0} 41^{\prime}\right.$ North latitude and $77^{\circ} 13^{\prime}$ 'East latitude, $228 \mathrm{~m}$ above mean sea level) Material for the study comprised of 44 genotypes of wheat were evaluated under late sowing with irrigation (heat stress) and without irrigation (combined heat \& drought stress) during 2016-17. The experiment was laid out in alpha lattice design with two replications in heat stress and combined stress conditions. The average temperatures of $28.6^{\circ} \mathrm{C}$ during the growing season and $30.2^{\circ} \mathrm{C}$ during the flowering period, with temperatures ranging from $24^{\circ} \mathrm{C}$ at night to $46^{\circ} \mathrm{C}$ at midday during flowering.

The soil moisture, temperature and precipitation during flowering to maturity stage are shown in Figure 1 and 2. Each genotype was planted with manually with gross plot size of $0.46 \times 2.5 \mathrm{~m}$, with rows at $23 \mathrm{~cm}$ apart. The experiment was carried out under well-watered and water-deficit conditions. The date of sowing in the month of December $8^{\text {th }}, 2016$ which was late or delayed sown in order to get terminal heat stress.

In the well-watered treatment (subsequently referred to as heat-stress treatment), plants were continuously irrigated throughout the cropping season. In the drought-deficit treatment (subsequently referred to as combined heat and drought stress treatment). The standard cultivation practices prescribed for wheat under irrigated conditions were followed precisely. 


\section{Measurements and analyses}

\section{Soil moisture measurements}

Soil samples from each experimental unit were collected in aluminium boxes with secure lids every week interval at three depths $(15,30$ and $45 \mathrm{~cm})$ by using augers. The samples were weighed immediately and then oven dried at $105{ }^{\circ} \mathrm{C}$ for $72 \mathrm{~h}$ for determining soil moisture content by gravimetric method and it has correlated with neutron moisture meter readings (Fig. 1).

\section{Weather parameters}

The different weather parameters during wheat crop growing season for the period 2016-2017 measured were daily maximum temperature $\left({ }^{\circ} \mathrm{C}\right)$, minimum temperature $\left({ }^{\circ} \mathrm{C}\right)$, RH maximum (\%), RH minimum (\%), rain $(\mathrm{mm})$, average wind speed (AWS), evapotranspiration and sunshine hours (Fig. 3)

\section{NDVI and canopy temperature measurements}

The NDVI measurements were taken three times in season with different crop growth stages viz., anthesis, grain filling, and maturity using a hand-held Ntech 'Greenseeker' (Field portable NDVI sensor). The NDVI was calculated based on wavelengths measured with the multispectral sensor. The canopy temperature was recorded during crop grain filling stage on all replications using the Sixth Sense LT300 IRT (Hand-held IRT, Mikron M90, Mikron Infrared Instrument Company Inc., Oakland, NJ, USA). Two NDVI and CT measurements were taken per plot, one on each bed. The two measurements were then averaged to obtain one final reading per plot. All NDVI and CT measurements were taken at midday (12 pm-2 pm) on clear, sunny days with minimal wind when the plant is most water stressed.
Grain yield (gm/plot) was determined on whole plots by combine harvesting when grains were dry at about $4 \%-5 \%$ moisture, and weighing the grains.

\section{Result and Discussion}

\section{Effect of soil moisture on canopy temperature}

Canopy temperature for all the forty-four genotypes was recorded throughout the growing period in delayed sown well-watered (heat stress) as well as delayed sown water stress (combined heat and drought stress) conditions. Area under curve plotted with minimum temperature observed in the canopy vs days after anthesis (DAA) indicated that canopy temperature did not vary across the genotypes. However, soil moisture deficit did not significantly affect the canopy temperature of the genotypes Duram and GW 322. In Westonia and HD 2864 genotypes canopy temperature was higher under combined stress plots.

The mean soil moisture in the heat and combined stress plots were 16.87 and 7.78 (\%) respectively. The range of soil moisture in heat stress plots were 14.84 to 19.12 (\%) during maturity and anthesis stage respectively. The range of soil moisture in combined stress plots were 05.08 to 10.49 (\%) during maturity and anthesis stage respectively (Fig. 1).

The mean NDVI in heat stress and combined stress genotypes were 0.57 and 0.50 respectively. The NDVI in the heat stress genotypes was higher compare to the combined stress. The $13 \%$ higher NDVI was observed in the heat stress genotypes (Fig. 4). The mean $\mathrm{CT}$ in heat stress and combined stress genotypes were $24.11^{\circ} \mathrm{C}$ and $29.47^{\circ} \mathrm{C}$ respectively. The $\mathrm{CT}$ in the heat stress genotypes was lower compare to the combined stress. The $18 \%$ lower CT was observed in 
the heat stress genotypes (Fig. 5). The mean grain yield per plot in heat stress and combined stress genotypes were 106.7 and $123.4 \mathrm{gm} /$ plot respectively. The grain yield in the heat stress genotypes was lower compare to the combined stress. The $13.5 \%$ lower grain yield was observed in the heat stress genotypes (Fig. 6). The difference in the NDVI readings taken at the anthesis and the maturity stage are negatively correlated with the final grain yield of heat stress genotypes (Fig. 7 and 8).

\section{The normalized differential vegetation index}

The difference in the NDVI readings under heat stress at anthesis and maturity stage genotypes Viz., Duram, GCP 36, DBW 43, HD 2985 and HD 2932 were lower with 0.12, $0.13,0.16,0.17$ and 0.18 respectively. The difference in the NDVI readings under heat stress at anthesis and maturity stage genotypes Viz., NP 4, GCP 16, HD 2329, Hindi 62 and GCP 1 were higher with $0.30,0.30,0.30,0.34$ and 0.35 respectively. The difference in the NDVI readings under combined stress at anthesis and maturity stage genotypes Viz., C 306, Chiriya 7, Kalyan sona, Raj 3765 and DBW 43 were lower with0.20, 0.23, 0.23, 0.23 and 0.24 respectively. The difference in the NDVI readings under combined stress at anthesis and maturity stage genotypes Viz., PBW 550, WH 730, HD 2329, Westonia and HD 2851 NDVI were lower with 0.37, 0.38, $0.39,0.39$ and 0.39 respectively. The NDVI was higher under the heat stress than the combined stress (Fig. 4).

\section{The canopy temperature}

The genotypes were showing lower CT value under heat stress Viz., GCP 16, NP 818, GCP 2, GW 322 and HD 3086 with 22.3, 22.4, $22.4,22.5$ and $22.6^{0} \mathrm{C}$ respectively. The genotypes were showing lower CT value under combined stress Viz., Duram, GW 322,
NP 818, C 306 and HD 2932 with 27.1, 27.2, $27.5,27.9$ and $27.9^{\circ} \mathrm{C}$ respectively. The genotypes were showing higher CT value under heat stress Viz., WR 544, Westonia, Babax, HD 2733 and Chiriya 7 with 26.1, 26.1, 26.2, 26.3 and $27.0^{\circ}$ Crespectively. The genotypes were showing higher CT value under combined stress Viz., Kundan, GCP 30, Babax, HD 2864 and Westonia with 30.7, $31.3,31.3,31.8$ and $31.8^{0} \mathrm{C}$ respectively. The Canopy temperature was higher under the combined stress than the heat stress (Fig. 5).

\section{The grain yield}

The genotypes were showing lower grain yield under heat stress Viz., GCP 30, GCP 16, GCP 23, Westonia and GCP 2 with 35.2, 36.5, 37.2, 38.7 and $45.5 \mathrm{gm} /$ plot respectively.

The genotypes were showing lower grain yield value under combined stress Viz., NP 818, GCP 16, GCP 30, GCP 23 and Westonia are 53.5, 67.6, 71.6, 72.1 and $88.7 \mathrm{gm} /$ plot respectively.

The genotypes were showing higher grain yield value under heat stress Viz., Chiriya 3, GCP 6, HI 1544, GW 322 and HD 2733 with $171.2,172.2,180.1,182.5$ and $195.7 \mathrm{gm} / \mathrm{plot}$ respectively.

The genotypes were showing higher grain yield value under combined stress Viz., HD 2987, GCP 6, Raj 3765, HD 3086 and Chiriya 7 with $168.0,172.2,172.5,173.5$ and 175.5 $\mathrm{gm} /$ plot respectively. The grain yield was higher under the combined stress than the heat stress (Fig. 6).

\section{Statistical analysis}

All statistical analyses were done using procedures in SAS v9.3 (SAS Institute Inc., Cary, NC, USA) with each treatment (heat and combined stress) analysed separately (Table $1)$. 


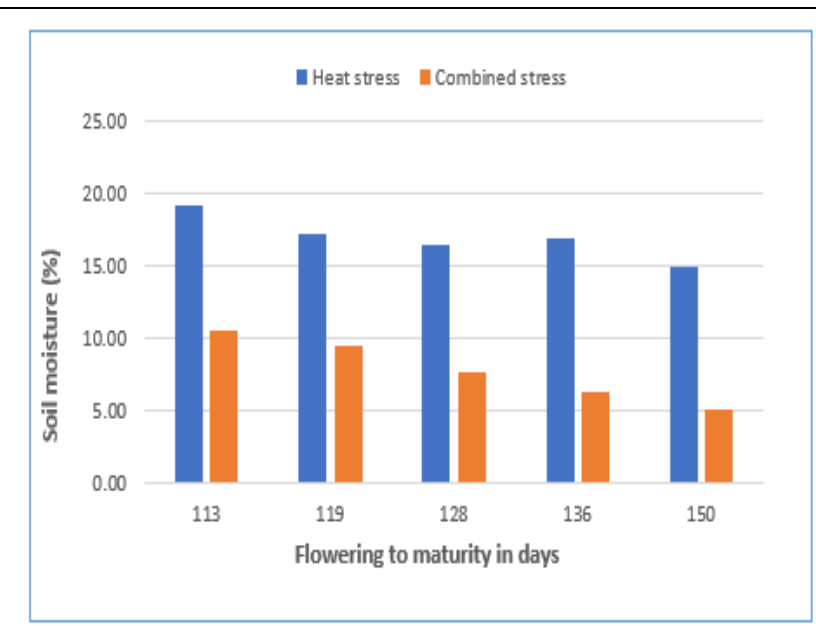

Fig. 1 The soil moisture measured in the wheat season flowering to maturity (days)

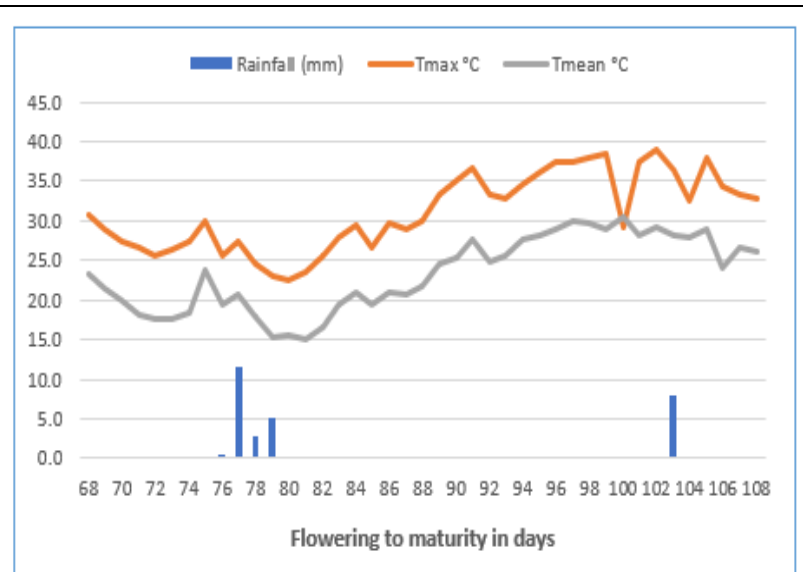

Fig. 2 Daily mean (light line) and maximum temperature (dark line) and precipitation (bars) measured throughout the wheat flowering to maturity (days)

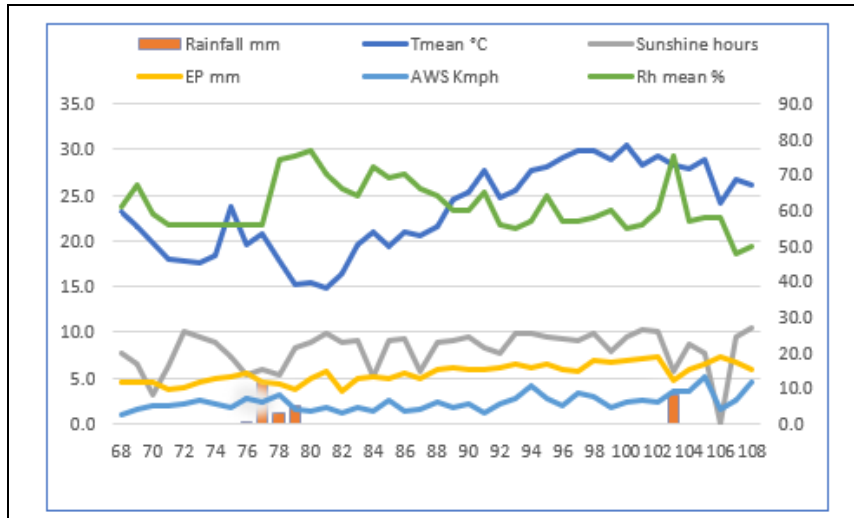

Fig. 3 Different weather parameters during wheat crop growing season for the period 2016-2017

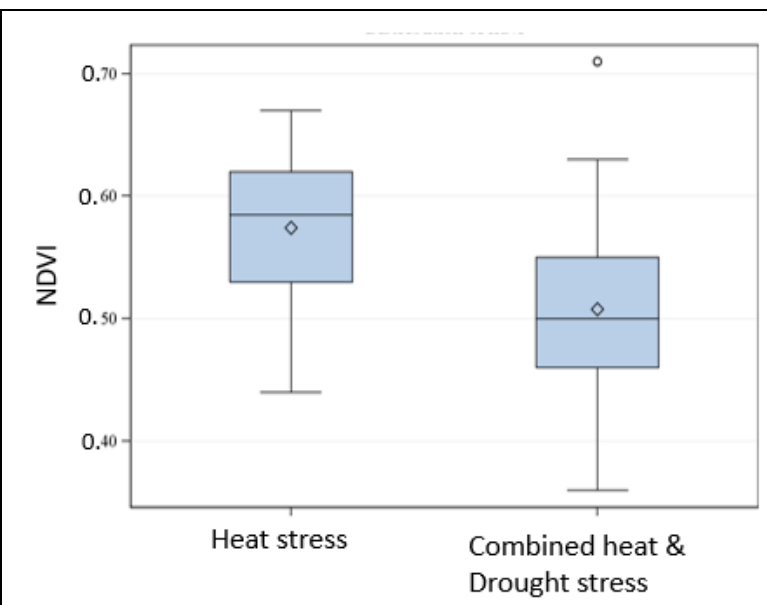

Fig. 4 NDVI under both heat and combined stress.

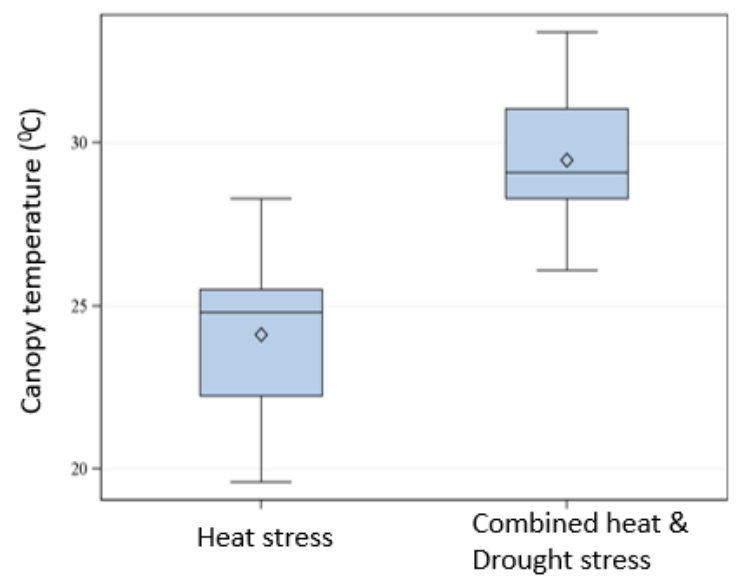

Fig. 5 Canopy temperature under both heat and combined stress. 

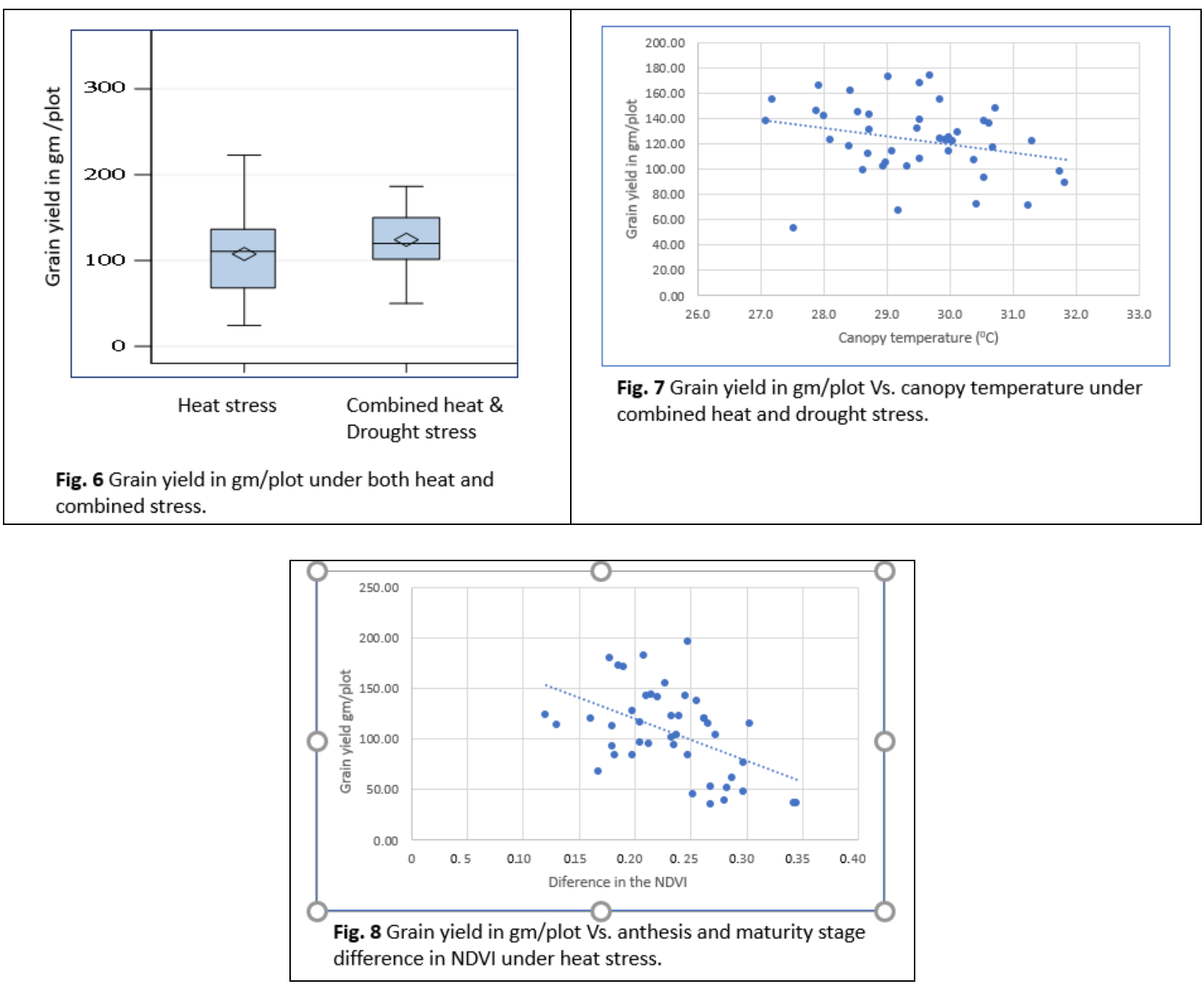

Table.1 The mean NDVI, canopy temperature, grain yield and soil moisture under heat and combined stress

\begin{tabular}{|l|l|l|l|l|}
\hline Condition & NDVI & CT $\left({ }^{\circ} \mathrm{C}\right)$ & $\begin{array}{l}\text { Yield } \\
(\mathrm{gm} / \mathrm{plot})\end{array}$ & $\begin{array}{l}\text { Soil moisture } \\
(\%)\end{array}$ \\
\hline $\begin{array}{l}\text { Heat stress } \\
\text { Combined heat \& } \\
\text { drought stress }\end{array}$ & 0.57 & 24.11 & 106.71 & 16.87 \\
\hline
\end{tabular}

Analysis of variance using PROC MIXED was carried on the forty-four genotypes to determine sources of variation within and across trials and determine if genotype by trial interaction was present for the traits measured. All effects in the model (rep, incomplete block, trial, entry $\mathrm{x}$ trial) with the exception of entries were treated as random.
Data from all trials was then normalized relative to the performance of RoelfsF2007 and used for further analysis of all entries across trials, similar to methods used to analyse historical trial data over years with a recurrent check (Graybosch and Peterson, 2010). PROC CORR was used to determine the phenotypic correlation between relative 
means of traits. Regression was performed using PROC REG to determine the relationship between $\mathrm{CT}$ and yield within each trial individually and across all trials. Initially, regression was used to determine the ability of CT and NDVI to predict yield. The interactions of days to heading and plant height with CT and NDVI were then fit as covariates (PROC ANCOVA) in the regression model to determine their effect on the yield predictability of CT and NDVI. The normalized differential vegetation index (NDVI) and the canopy temperature (CT)are efficient low-cost measurement of crop water status and soil water status that has potential for phenotypic selection of stress tolerant and susceptible lines. Overall, cooler CT was favourable for higher yield although this association was stronger and more consistent under heat stress.

The lower NDVI and higher canopy temperature under the combined heat and drought stress resulted in higher yield because of plants wants complete their reproductive cycle very fast during the combined stress. The higher NDVI, lower canopy temperature, more vegetative growth and reproductive cycle coincided with the terminal heat stress resulted in lesser yield under heat stress compare with the combined stress.

Variation in the coefficient of determination and the slope across individual trials indicates that genetic background plays a definite role in the ability of CT and NDVI to predict yield and thus background information on the parents of a breeding line may help in making decisions on interpreting the results of CT measurements. The most useful implementation of CT and NDVI for genetic improvement would be in the early generations of breeding, such as on progeny rows where yield testing is not performed, although considerations would need to be made for an experimental design that utilizes a repeated check cultivar to adjust for spatial variation. In the future, high throughput tools for measuring CT and NDVI that increase speed and accuracy will also allow breeders to maximize potential genetic gain from $\mathrm{CT}$ and NDVI.

An innovative method to evaluate wheat genotypes under high temperatures and combined heat and drought stress using Greenseeker and Sixth Sense LT300 IRT. This cost-effective technique allows the phenotyping of large populations in a short time period. The use these instruments reduces the time needed for the measurement of NDVI using a Greenseeker (Cairns et al., 2012) or visual scores (White et al., 2012) from 30 seconds per plot to the fraction of a second per plot.

\section{Effects of heat under well-watered conditions vs. restricted water access during grain filling on grain yield}

Relative to heat stress carried out under delayed sown in order to get terminal heat stress temperatures, grain yield was increased by $13.6 \%$ under combined heat and drought stress than the heat stress. These results are in not agree with results obtained by (Lobell et al., 2011), showing that each degree-day accumulated above $30^{\circ} \mathrm{C}$ reduced the final yield by $1 \%$ under optimal rain-fed conditions, and by $40 \%$ under drought-stress conditions. Optimal temperature for tropical maize is around $35^{\circ} \mathrm{C}$ (Cichino, Rattalino Edreira, and Otegui 2010), whereas average temperatures measured in our study reached up to $45^{\circ} \mathrm{C}$ under heat stress and $54^{\circ} \mathrm{C}$ under combined heat and drought stress. Under well-watered conditions, increases in temperature above $45^{\circ} \mathrm{C}$ have been shown to reduce photosynthesis by $50 \%$ (Crafts Brandner and Salvucci 2002), potentially explaining the strong reductions in grain yield under high temperatures than the combined stress observed here. 


\section{NDVI and canopy temperature allow identification of tolerant genotypes}

The NDVI explained differences between and within treatments, whereas canopy temperature explained differences in grain yield among treatments and genotypes within the combined heat and drought stress treatment. Under combined heat and drought stress, our results showed positive correlations between canopy temperature and grain yield, indicating that genotypes that show higher canopy temperature under combined high temperatures and drought stress yielded higher because of the higher stem reserve mobilization. Canopy temperature has been used to identify germplasm with increased tolerance to high temperatures in wheat (Cossani and Reynolds 2012). The method presented here would therefore allow the identification of genotypes tolerant to conditions encountered in the farmers' fields. The correlation measured between $\mathrm{CT}$ and grain yield is reflective of the importance of sufficient assimilate availability for yield formation under combined stress $(r=0.275)$. The negative correlation measured between difference in NDVI and grain yield under combined stress $(r=286)$. In our study, beneficial effects of a high NDVI on grain yield may have been boon under combined heat and drought stress by reduced stem reserve mobilization.

\section{References}

Barnabas, B., K. Jaeger, and A. Feher. 2008. The effect of drought and heat stress on reproductive processes in cereals. Plant Cell and Environment. 31:11- 38.

Cairns, J. E., J. Crossa, P. H. Zaidi, P. Grudloyma, C. Sanchez, J. L. Araus, S. Thaitad, D. Makumbi, C. Magorokosho, M. Banziger, A. Menkir, S. Hearne, and G. N. Atlin.2013. Identification of drought, heat, and combined drought and heat tolerant donors in maize. Crop Science. 53:1335- 46.

Cairns, J. E., J. Crossa, P. H. Zaidi, P. Grudloyma, C. Sanchez, J. L. Araus, S. Thaitad, D. Makumbi, C. Magorokosho, M. Banziger, A. Menkir, S. Hearne, and G. N. Atlin. 2013. Identification of drought, heat, and combined drought and heat tolerant donors in maize. Crop Science. 53:1335-46.

Cairns, J., C. Sanchez, M. Vargas, R. Ordoñez, and J. L. Araus. 2012. Dissecting maize productivity: Ideotypes associated with grain yield under drought stress and well watered conditions. Journal of Integrative Plant Biology. 54:1007-20.

Cichino, M., J. I. Rattalino Edreira, and M. E. Otegui. 2010. Heat stress in field-grown maize: Response of physiological determinants of grain yield. Crop Science. 50:1438-48.

Cossani, C. M., and M. P. Reynolds. 2012. Physiological traits for improving heat tolerance in wheat. Plant Physiology 160:1710-18. doi:10.1104/pp.112. 207753.

Crafts-Brandner, S. J., and M. E. Salvucci. 2002. Sensitivity of photosynthesis in a C4 plant, maize, to heat stress. Plant Physiology. 129:1773-80.

Crafts-Brandner, S. J., and M. E. Salvucci. 2002. Sensitivity of photosynthesis in a C4 plant, maize, to heat stress. Plant Physiology. 129:1773-80.

Garrity, D. P., and J. C. O' Toole. 1995. Selection for reproductive stage drought avoidance in rice, using infrared thermometry. Agronomy Journal. 87:773- 79

Graybosch, R.A., Peterson, C.J. 2010. Genetic improvement in winter wheat yields in the great plains of North America, 1959-2008. Crop Sci. 50, 1882-1890.

Henik, J. J., A. D. Knapp, K. J. Moore, and C. Lee. 11s. Burras, 2012: Normalized 
difference vegetative index used to identify spatial variability in vegetative growth and grain yield of corn. Crop Management. 1:0824-01.

Jackson, R.D., Reginato, R.J., Idso, S.B.1977. Wheat canopy temperature-Practical tool for evaluating water requirements. Water Resour. Res. 13, 651-656.

Khabarov, N., et al., 2014. Assessing agricultural risks of climate change in the 21 st century in a global gridded crop model intercomparison. Proc. Natl. Acad. Sci. 111, 3268-3273.

Lobell, D. B., M. Banziger, C. Magorokosho, and B. Vivek. 2011. Nonlinear heat effects on African maize as evidenced by historical yield trials. Nature Climate Change. 1:42-45.

Neiff, N., Dhliwayo, T., Suarez, E. A., Burgueno, J., and Trachsel, S. 2015. Using an airborne platform to measure canopy temperature and NDVI under heat stress in maize. Journal of Crop Improvement. 29(6), 669-690.

Porter, J.R., Xie, L., Challinor, A.J., Cochrane, K., Howden, S.M., Iqbal, M.M., Travasso, M.I. 2014. Food security and food production systems. In Climate Change-Impacts, Adaptation and Vulnerability. Part a global and sectoral aspects; contribution working group ii to fifth assessment report; intergovernmental panel on climate change: Geneva, Switzerland, 2014; pp. 485-533.

Rattalino Edreira, J. I., and M. E. Otegui. 2012. Heat stress in temperate and tropical maize hybrids: Differences in crop growth, biomass partitioning, and reserves use. Field Crops Research. 130:87-98.

Reynolds, M., Manes, Y., Izanloo, A., Langridge, P. 2009. Phenotyping approaches for physiological breeding and gene discovery in wheat. Ann. Appl. Biol. 155, 309-320.

Rizhsky, L., H. J. Liang, and R. Mittler. 2002. The combined effect of drought stress and heat shock on gene expression in tobacco. Plant Physiology. 130:114351.

Tucker, C.J. 1979. Red and photographic infrared linear combinations for monitoring vegetation. Remote Sens. Environ. 8, 127-150.

Weber, V. S., A. E. Melchinger, C. Magorokosho, D. Makumbi, M. Banziger, and G. N. Atlin. 2012. Efficiency of managed-stress screening of elite maize hybrids under drought and low nitrogen for yield under rainfed conditions in Southern Africa. Crop Science. 52:1011-20.

White, J., P. Andrade-Sanchez, M. Gore, K. Bronson, T. Coffelt, M. Conley, K. Feldmann, D. A. Frencha, J. Heun, D. Hunsaker, M. Jenks, B. Kimball, R. Roth, R. Strand, K. T. G. Wall, and G. Wang. 2012. Field-based phenomics for plant genetics research. Field Crops Research, 133:101-12.

\section{How to cite this article:}

Gurumurthy, S., Ajay Arora, Basudeb Sarkar, Harikrishna, V.P. Singh, S.K. Meena, Prakash Kumar and Singh, P.K. 2018. Individual Heat and Combined Heat Drought Stresses in Wheat: Variation in NDVI and Canopy Temperature. Int.J.Curr.Microbiol.App.Sci. 7(10): 2676-2684. doi: https://doi.org/10.20546/ijcmas.2018.710.311 